\title{
Invitro Conservation of Zingiber Officinale through rhizome
}

\author{
Sharma Kadambari*, Malik Bhawna* \\ * Dept. of Biotechnology, Govt. Madhav Science College, Ujjain (M.P.)
}

\begin{abstract}
Ginger (Zingiber officinale Rosc.) is a perennial herb. It belongs to the family Zingiberaceae and commercially cultivated in most tropical regions of the world. The underground rhizomes are the planting materials in a conventional propagation of ginger however it has a low multiplication rate. It is known that there are possible methods are available for rapid vegetative propagation of ginger through direct organogenesis or somatic embryogenesis under in vitro conditions but it is necessary to find the best protocol for in vitro multiplication of ginger. However, significant efforts have been made in the procedure for in vitro micro propagation in the other ginger growing countries. The available literature with respect to in vitro plant regeneration has been perused and this review mainly focused on the in vitro propagation via direct organogenesis from rhizome buds or shoot tips of ginger often used as explants. In vitro techniques are increasingly being employed to conserve vegetatively propagated crops in various germplasm conservation programs. These are specifically applied to crops where the seeds are recalcitrant (seeds which get killed on drying and freezing), seeds are not formed. In vitro technique has several advantages: In contrast to clonal repositories or field gene bank, in vitro repositories offer safety from environmental vagaries and widespread diseases. The main advantage of the technique is the ability to regenerate disease free, true to type plants at high frequency from axillary buds, shoot tips and meristems.
\end{abstract}

Keywords: In vitro, germplasm, regeneration, rhizome and micropropagation.

\section{Introduction}

In vitro approaches for the conservation and the use of plant germplasm can offer some distinct advantage over alternative strategies. Some of these are as follows: (1) collection may occur at anytime independent of flowering period for each species (this assumes that seed material is not required), (2) there is the potential of virus elimination from contaminated tissue through meristem culture, (3) clonal material can be produced where this is useful for the maintenance of elite genotypes, (4) rapid multiplication may occur at any time where stocks are required using micro propagation procedures, (5) germination of difficult or immature seed or embryo may be facilitated for breeding programmes, and (6) distribution across the border may be safer, in terms of germplasm health status using in vitro cultures. Some more general positive advantages of in vitro techniques include the fact that storage space requirements are vastly reduced compared with field storage. Storage facilities may be established at any geographical location and cultures are not subject to environmental disturbances such as temperature fluctuation, cyclones, insect, pests, and pathogen

The present investigation deals with collection and in vitro conservation of ginger, slow growth of culture as well as induction of in vitro rhizome has been successfully employed for conservation of its germplasm. For the present work, experiments were carried out to study in vitro rhizome induction in a few accession of ginger, and to study the growth, development and regeneration of the in vitro produced rhizomes. So the work presented here will be beneficial for the biological conservation as well as for the worldwide pharmaceutical industry as it has also medicinal importance[1,2].

\section{Material and Methods}

The shoot cultures of ginger previously established in the lab were used for initiating in vitro rhizomes. For induction of rhizomes, 4 week old culture were used. The medium was used was MS+BAP $(1 \mathrm{mg} / \mathrm{l})+\mathrm{NAA}(0.1 \mathrm{mg} / \mathrm{l})$ with $12 \%$ sucrose and $0.8 \%$ agar(Bhat et al.,1994). Cultures were grown in test tubes with $20 \mathrm{ml}$ medium per tube. Induction of rhizome took 6-12 months. Shoots were removed and individual number of rhizomes per culture were counted and measured. The mean value and standard deviation for number of rhizome per culture, and width of rhizome were calculated[3]. 


\begin{tabular}{|l|l|l|l|}
\hline S.No. & Culture No. & Range of rhizomes(no) & Range in size of rhizomes(mm) \\
\hline 1 & Z-6 & 5 & 7 \\
\hline 2 & Z-9 & 5 to 10 & 2 to 14 \\
\hline 3 & Z-13 & 5 to 6 & 7 \\
\hline 4 & Z-35 & 3 to 5 & 4 to 15 \\
\hline 5 & Z-50 & 8 to 11 & 8 to 10 \\
\hline 6 & Z-51 & 5 to 9 & 4 to 13 \\
\hline 7 & Z-56 & 2 to 5 & 5 to 15 \\
\hline 8 & Z-64 & 4 to 6 & 10 to 20 \\
\hline 9 & Z-77 & 4 & 5 to 15 \\
\hline 10 & Z-89 & 10 & 9 to 20 \\
\hline
\end{tabular}

The in vitro harvested rhizomes were then used for studying regrowth and shoot formation. Rhizomes were germinated in petriplate with moist filter paper as well as in tissue culture media. For in vitro induction of bud break and shoot proliferation, the following two media were tested[4]:

g 1:MS salts $+2.5 \mathrm{mg} / \mathrm{mlBAP}+0.25 \%$ phytagel $+3 \%$ sucrose

$\mathrm{P} 4$ : MS salts $+22.5 \mathrm{mg} / \mathrm{mlBAP}+1 \mathrm{mg} / \mathrm{ml}$ ascorbic acid $+0.25 \%$ phytagel $+3 \%$ sucrose

Cultures were incubated at $25 \pm 22^{\circ} \mathrm{C}$ under a $16 \mathrm{~h}$ photoperiod, provided by $40 \mathrm{~W}$ cool day light flouroscent tube lights, adjusted $30 \mathrm{~cm}$ above the culture tubes, giving a light intensity of 2000-3000 lux. Data was recorded 3 weeks after culture.

\section{Result and Discussion}

Ginger shoot cultures grew well on the MS medium supplemented with $12 \%$ sucrose. In the first three months, only shoots and roots were observed. Swelling of the basal portion and appearance of incipient rhizomes was observed from the fourth month onwards. The number of rhizomes per culture varied from 2 to 25 , depending on the genotype. Rhizome width varied from 4-20 mm. P4 medium was found to be better for bud break in ginger rhizomes. Within 3-4 days of culture, bud break was observed in rhizomes cultured on P4 medium. In g 1 medium sprouting occurred after 7-10 days. Thus higher BAP concentration was found beneficial for sprouting of in vitro rhizomes of ginger [5]

\section{Conclusion}

The rhizomes harvested from in vitro cultures did not exhibit dormancy and readily sprouted shoots upon their placements in moist filter papers Medicinal plants are under the threat of overexploitation and biodiversity depletion. There is urgent need of their invitro conservation. Collection and in vitro conservation of medicinally important plants in the present study opens fresh avenues towards the conservation and resource management of the overexploited medicinal plants[6,7].

\section{Bibliography}

[1]. M. R. W. Rands, W. M. Adams, L. Bennun et al., "Biodiversity conservation: challenges beyond 2010,"Science, vol. 329, no. 5997, pp. 1298-1303, (2010).

[2]. B. Nandagopal, S. Sankar, M. Ramamurthy, S. Sathish, and G. Sridharan, "Could the products of Indian medicinal plants be the next alternative for the treatment of infections?" Indian Journal of Medical Microbiology, vol. 29, pp. 93-101, (2011).

[3]. Behera, K.K., O. Pani and S. Sahoo, Effect of plant growth regulator on in vitro multiplication of turmeric (Curmuma lomga L. cv Ranga). Int. J. Biol. Technol., 1: 16-23(2010).

[4]. Lincy, A. and B. Sasikumar, Enhanced adventitious shoot regeneration from aerial stem explants of ginger using TDZ and its histological studies. Turk. J. Bot., 34: 21-29(2010).

[5]. Villamor, C.C., Influence of media strength and sources of nitrogen on micropropagation of ginger, Zingiber officinale Rosc. E-Int. Sci. Res. J., 2: 150-155(2010.).

[6]. Thayamini H. Seran ,. In vitro Propagation of Ginger (Zingiber officinale Rosc.) through Direct Organogenesis: A Review. Pakistan Journal of Biological Sciences, 16: 1826-1835(2013).

[7]. Bhagyalakshmi, A. and N.S. Singh, Meristem culture and micro propagation of a variety of ginger (Zingiber officinale Rosc.) with a high yield of Oleoresin. J. Hort. Sci., 63: 321-3279(1988), 